(6)

\section{OPEN ACCESS}

- An additional appendix is published online only. To view this file please visit the journal online (http://dx.doi.org/ 10.1136/jech-2011-200856).

${ }^{1}$ Institute of Health and Wellbeing, University of Glasgow, Royal Hospital for Sick Children, Glasgow

${ }^{2}$ ScotCen Social Research,

Edinburgh, UK

${ }^{3}$ NatCen Social Research,

London, UK

${ }^{4} \mathrm{MRC}$ Social and Public Health

Sciences Unit, Glasgow, UK

Correspondence to

Dr Philip Wilson, University of Glasgow, Caledonia House,

Royal Hospital for Sick Children,

Glasgow G3 8SJ, UK;

philip.wilson@glasgow.ac.uk

Accepted 11 June 2012

Published Online First

27 July 2012

\title{
What predicts persistent early conduct problems? Evidence from the Growing Up in Scotland cohort
}

\author{
Philip Wilson, ${ }^{1}$ Paul Bradshaw, ${ }^{2}$ Sarah Tipping, ${ }^{3}$ Marion Henderson, ${ }^{4}$ Geoff Der, ${ }^{4}$ \\ Helen Minnis ${ }^{1}$
}

\begin{abstract}
Background There is a strong case for early

identification of factors predicting life-course-persistent conduct disorder. The authors aimed to identify factors associated with repeated parental reports of preschool conduct problems.
\end{abstract}

Method Nested case-control study of Scottish children who had behavioural data reported by parents at 3, 4 and 5 years.

Results 79 children had abnormal conduct scores at all three time points ('persistent conduct problems') and 434 at one or two points ('inconsistent conduct problems'). 1557 children never had abnormal scores. Compared with children with no conduct problems, children with reported problems were significantly more likely to have mothers who smoked during pregnancy. They were less likely to be living with both parents and more likely to be in poor general health, to have difficulty being understood, to have a parent who agrees that smacking is sometimes necessary and to be taken to visit other people with children rarely. The results for children with persistent and inconsistent conduct problems were similar, but associations with poverty and maternal smoking were significantly less strong in the inconsistent group.

Conclusion These factors may be valuable in early identification of risk of major social difficulties.

\section{INTRODUCTION}

There is an increasingly strong case for screening preschool children for conduct disorder (CD), particularly 'life-course-persistent' $\mathrm{CD}^{2}{ }^{2}$ which emerges in early life and persists into adulthood with major adverse social, physical and health consequences. Difficulties present early in life are often predictive of behavioural problems and other negative health outcomes at later stages of childhood, adolescence and beyond. ${ }^{3-6}$ Furthermore, there are effective interventions for preschool children with behaviour problems, which can reduce the risk of developing more serious psychopathology. ${ }^{7}$ The main weakness in the argument for screening lies in the lack of a sufficiently sensitive and specific screening test for use with preschool children. ${ }^{1}$

Some data are available on predictors of CD during early childhood. The Copenhagen Child Cohort Study ${ }^{9}$ used combined contemporaneous questionnaire scores from parents and teachers of 5-7-year-old children and, using a multivariable model, found that male sex, extreme prematurity, young maternal age, low household income at the time of birth and the child living without any biological parents or with a single parent in the first year of life predicted likely psychopathology.

Murray et $a l^{10}$ recently summarised available data from cohort studies predicting conduct problems and crime. Their new analysis used data from the 1970 British Cohort Study on pregnancy and birth, and child, parent and socioeconomic characteristics at age 5 . Conduct problems were reported by parents at age 10, and criminal convictions were self-reported by study members at age 30 . Among pregnancy and birth measures, only prenatal maternal smoking was strongly predictive of conduct problems and criminal conviction. There were, however, several strong psychosocial risk factors identifiable during the preschool period (up to age 5): parental loss, low cognitive stimulation, maternal depression, having a teenage mother or single mother at birth and living in a large family or poor neighbourhood

In identifying predictors of life-course-persistent $\mathrm{CD}$, we require both robust early assessment data, available only in a few cohort studies, ${ }^{11}$ and evidence of longitudinal stability of children's difficulties. The Growing Up in Scotland (GUS) study (http://www.growingupinscotland.org.uk) is a recent source of data describing factors involved in children's social, emotional and behavioural development up to entry to primary school-usually around age 5 in Scotland. The Strengths and Difficulties Questionnaire (SDQ) $)^{12-14}$ was completed at ages 3, 4 and 5 years for all GUS participants. This 25-item questionnaire (http:// www.sdqinfo.org) is a very widely used screening tool for psychiatric disorder in children aged $3-16$ years. It can be completed by parents or teachers of young children, and it is the parentreported version that is described here. A systematic review of studies comparing SDQ scale scores with psychiatric diagnosis ${ }^{15}$ reported that parentreported versions of the SDO conduct problems subscale have sensitivity of 0.75 and specificity of 0.91 for the detection of CDs. The outcome of interest in the present paper is persistently abnormal conduct scores at ages 34, 46 and 58 months, which we believe may be a good proxy for life-course-persistent CD. Future waves of data may allow this conjecture to be further tested using a range of modelling approaches to $\mathrm{CD}$ trajectories over time. ${ }^{16} 17$

This study aims to identify predictors of CD by assessing associations between persistently abnormal SDQ conduct problem scores with characteristics drawn from candidate predictors in the published literature. 


\section{METHODS}

\section{The Growing Up in Scotland study}

We analysed data from the families who completed the first four sweeps (2005/2006 to 2008/2009) of the 'child cohort' of GUS. Focusing initially on a cohort of 2859 children aged 2-3 years, the first wave of fieldwork began in April 2005 and annual data collection has been undertaken since that time.

The study population was derived from child benefit records (at that time around $97 \%$ of eligible families were in receipt of this benefit in Scotland). Stratified cluster sampling was used to derive a nationally representative sample. Primary sampling units (PSUs) were first created by aggregating data zones (small, relatively socially homogeneous, geographical areas of adjacent postcodes with 500-1000 residents) in order to give an average of 57 births per sampling unit per year based on the previous 3 years birth rates in the relevant data zones. PSUs were then stratified according to local authority area and then Scottish Index of Multiple Deprivation score. One hundred and thirty PSUs were then randomly selected across strata to ensure a representative mix of areas in terms of socioeconomic status and local authorities.

$\mathrm{SDO}^{14}$ data were obtained via parental report, normally from the mother, in the computer-assisted self-completion module of the interview. Three sets of data were available, measured at ages 34, 46 and 58 months. SDO data were processed using the standard algorithm for parent-completed questionnaires provided at the website (http://www.sdqinfo.org). The SDO scores were dichotomised, with a value of 4 or more being considered abnormal and indicative of possible $\mathrm{CD}$. Then, three groups of children were defined according to whether they had abnormal SDQ conduct scores on: none, some or all three of the occasions. This three-way classification was used as our principal outcome variable and we refer to the groups below as: 'never', 'inconsistent' and 'persistent' conduct problems.

\section{Statistical methods}

Unless otherwise stated, all items were measured at the first contact when the cohort child was aged around 34 months. Numbers (except those reflecting the actual number of children belonging to each $\mathrm{CD}$ category) were weighted to adjust for non-response and sample selection.

Tables were created in SPSS V.18 using the Complex Samples module and the regression analyses were run in Stata using the survey (svy) command. Both sets of commands generate robust SEs that take sample design features, such as clustering, into account. The commands identify the sample clusters; the between- and within-cluster variances are then used to generate robust SEs.

A multinomial logistic model was used for the principal analysis. The never abnormal group was chosen as the reference category, and the results are presented as two sets of ORs: one contrasting the inconsistently abnormal group with the never abnormal group and the other contrasting the persistent group with the never abnormal group. Similar results, in terms of ORs, would be obtained by fitting two binary logistic models, and it may be convenient to interpret the results as such. The multinomial model nevertheless has the advantage of being more efficient and hence yielding narrower $\mathrm{CIs} .{ }^{18} \mathrm{~A}$ more parsimonious ordinal logistic model was also tested, but the proportional odds assumption that underlies it was not tenable and so the results from the multinomial model were retained. Unadjusted ORs were estimated without controlling for other variables. All variables with sufficient numbers of cases were then included in a multivariable model to produce the adjusted ORs.

\section{Ethics approval}

The initial sweep of data collection was subject to medical ethical review by the Scotland 'A' MREC committee (application reference: 04/M RE $10 / 59$ ). Subsequent annual sweeps have been reviewed via substantial amendment submitted to the same committee.

\section{RESULTS}

Our sample was restricted to those 2070 cases with valid SDO conduct subscale scores at each sweep of data collection (34, 46 and 58 months) $-72.2 \%$ of the cohort as a whole. Numbers of children with abnormal conduct scale scores at each data collection point are shown in table 1 .

Table 2 gives univariate comparisons of the characteristics of the children with persistent conduct problems and those with inconsistent conduct problems, and their families, with the children who did not have abnormal scores at any time. The multinomial model, adjusted for all variables, is also presented here. Variables are described in online appendix 1.

The interaction can be interpreted in terms of ORs, which compare the four groups defined by maternal smoking during pregnancy and household income. Taking the mothers who had higher income and did not smoke during pregnancy as the reference group, the ORs for inconsistent and persistent conduct problems, respectively (compared with no conduct problems) are: for higher income with antenatal smoking 1.52 vs 5.02; for low income without antenatal smoking 1.34 vs 4.33 and for low income with antenatal smoking 1.77 vs 4.47 .

Analysis using the unweighted data yielded very similar results, and the data are available from the corresponding author on request.

As noted above, the analysis was also undertaken using ordinal logistic regression methods, which treat the outcome variable (no conduct problems, inconsistent problems, persistent problems) as ordered. The Brant test for proportional odds ${ }^{19}$ indicated that the assumptions required for the ordinal model were violated and so the results are not presented in detail here. In brief, the association between maternal smoking during pregnancy, living in a family in the lowest income quintile and the interaction between maternal smoking and low income was shown to be significantly different for children in the persistent group compared with those in the inconsistent group.

\section{DISCUSSION}

We identified 79 children with abnormal conduct scores at ages 3 , 4 and 5 years: $4.3 \%$ of the whole cohort, and 434 (22.5\%) children

Table 1 Patterns of prevalence of abnormal scores on the SDQ conduct subscale over time

\begin{tabular}{|c|c|c|c|c|c|}
\hline \multicolumn{3}{|c|}{ 'Abnormal' score on SDQ at: } & \multirow{2}{*}{$\begin{array}{l}\text { Unweighted } \\
\text { number }\end{array}$} & \multirow{2}{*}{$\begin{array}{l}\text { Weighted } \\
\text { number }\end{array}$} & \multirow{2}{*}{$\begin{array}{l}\text { Per cent of } \\
\text { whole cohort } \\
\text { with valid } \\
\text { data }\end{array}$} \\
\hline 34 months & 46 months & 58 months & & & \\
\hline No & No & No & 1557 & 1510 & 73.1 \\
\hline No & No & Yes & 72 & 74 & 3.6 \\
\hline No & Yes & No & 98 & 104 & 5 \\
\hline No & Yes & Yes & 46 & 52 & 2.5 \\
\hline Yes & No & No & 126 & 132 & 6.4 \\
\hline Yes & No & Yes & 45 & 47 & 2.3 \\
\hline Yes & Yes & No & 47 & 56 & 2.7 \\
\hline \multirow[t]{2}{*}{ Yes } & Yes & Yes & 79 & 90 & 4.3 \\
\hline & & & 2070 & 2065 & 100 \\
\hline
\end{tabular}

Conduct scores ranged from 0 to 10 , scores in the 'abnormal' range being $\geq 4$ (www. sdqinfo.org/py/doc/c0.py).

SDQ, Strengths and Difficulties Questionnaire. 
Table 2 Occurrence of persistent abnormal conduct score by child and family characteristics

\begin{tabular}{|c|c|c|c|c|c|c|c|}
\hline & \multirow{2}{*}{$\begin{array}{l}\text { N (\%) } \\
\text { persistent } \\
\text { abnormal } \\
\text { conduct } \\
\text { score }\end{array}$} & \multirow{2}{*}{$\begin{array}{l}\mathbf{N}(\%) \\
\text { inconsistent } \\
\text { abnormal } \\
\text { conduct } \\
\text { score }\end{array}$} & \multirow{2}{*}{$\begin{array}{l}\text { N (\%) never } \\
\text { having } \\
\text { abnormal } \\
\text { conduct } \\
\text { scores }\end{array}$} & \multicolumn{2}{|c|}{ Unadjusted ORs and $\mathrm{Cl}$} & \multicolumn{2}{|l|}{ Adjusted $\mathrm{ORs}$ and $\mathrm{CI}$} \\
\hline & & & & $\begin{array}{l}\text { Inconsistent } \\
\text { versus never }\end{array}$ & $\begin{array}{l}\text { Persistent } \\
\text { versus never }\end{array}$ & $\begin{array}{l}\text { Inconsistent } \\
\text { versus never }\end{array}$ & $\begin{array}{l}\text { Persistent } \\
\text { versus never }\end{array}$ \\
\hline \multicolumn{8}{|l|}{ Sex of child } \\
\hline Male & $48(5)$ & $236(24)$ & $769(71)$ & & & & \\
\hline Female & $31(4)$ & $198(21)$ & $788(75)$ & $0.82(0.65$ to 1.03$)$ & $0.67(0.43$ to 1.04$)$ & 0.89 (0.68 to 1.14$)$ & $0.77(0.44$ to 1.35$)$ \\
\hline Other ethnicity & $1(2)$ & $13(24)$ & $42(74)$ & $1.05(0.49$ to 2.25$)$ & $0.43(0.06$ to 2.99$)$ & Dropped & Dropped \\
\hline \multicolumn{8}{|l|}{ Maternal age at child's birth } \\
\hline 25 years or older & $49(3)$ & $317(20)$ & $1291(77)$ & & & & \\
\hline Younger than 25 years & $26(7)$ & $114(31)$ & $247(62)$ & $1.91(1.52$ to 2.41$)$ & $2.6(1.57$ to 4.29$)$ & $1.38(1.05$ to 1.83$)$ & $1.38(0.76$ to 2.5$)$ \\
\hline \multicolumn{8}{|l|}{ No. of children in household } \\
\hline One & $20(4)$ & $123(20)$ & $521(76)$ & & & & \\
\hline \multicolumn{8}{|c|}{ No. of natural parents in household } \\
\hline One or none & $36(9)$ & $132(19)$ & $238(58)$ & 2.44 (1.89 to 3.15$)$ & 4.25 (2.81 to 6.42$)$ & 1.68 (1.13 to 2.51$)$ & 1.82 (1.12 to 2.94$)$ \\
\hline \multicolumn{8}{|l|}{ Household income (quintiles) } \\
\hline Other $(\geq £ 8410)$ & $46(3)$ & $303(20)$ & $1262(77)$ & & & & \\
\hline Bottom $(<£ 8410)$ & $25(9)$ & $94(35)$ & $154(56)$ & 2.37 (1.78 to 3.16$)$ & $3.98(2.37$ to 6.68$)$ & 1.34 (0.77 to 2.34$)$ & $4.33(1.72$ to 10.9$)$ \\
\hline \multicolumn{8}{|l|}{ Child's general health } \\
\hline Very good or good & $65(4)$ & $400(22)$ & $1502(75)$ & & & & \\
\hline Fair, bad or very bad & $14(15)$ & $34(35)$ & $55(50)$ & 2.44 (1.59 to 3.75$)$ & 6.04 (3.13 to 11.67$)$ & 1.75 (1.1 to 2.78$)$ & $2.41(0.9$ to 6.42$)$ \\
\hline \multicolumn{8}{|l|}{ Low birth weight } \\
\hline No & $68(4)$ & $403(22)$ & $1467(74)$ & & & & \\
\hline Yes & $9(8)$ & $28(25)$ & $86(67)$ & $1.21(0.79$ to 1.87$)$ & 2.21 (1.09 to 4.47$)$ & $1.1(0.67$ to 1.78$)$ & 1.28 (0.56 to 2.94$)$ \\
\hline \multicolumn{8}{|c|}{ No. of missed developmental milestones } \\
\hline None or one & $14(3)$ & $122(21)$ & $464(76)$ & & & & \\
\hline \multicolumn{8}{|c|}{ Agree that smacking is sometimes the only thing that will work } \\
\hline No & $35(3)$ & $231(20)$ & $941(77)$ & & & & \\
\hline Yes & $44(6)$ & $203(26)$ & $616(68)$ & $1.42(1.12$ to 1.79$)$ & $2.03(1.22$ to 3.37$)$ & $1.28(1.00$ to 1.64$)$ & $1.81(0.98$ to 3.31$)$ \\
\hline \multicolumn{8}{|c|}{ Frequency child taken to visit other people with children } \\
\hline Fortnightly or more often & $52(4)$ & $318(21)$ & $1250(75)$ & & & & \\
\hline Less often or never & $27(7)$ & $115(28)$ & $305(65)$ & $1.54(1.23$ to 1.93$)$ & $2.3(1.36$ to 3.88$)$ & $1.41(1.09$ to 1.81$)$ & $2.09(1.13$ to 3.85$)$ \\
\hline \multicolumn{8}{|l|}{ Frequency child is read to } \\
\hline Daily & $52(3)$ & $318(21)$ & $1250(76)$ & & & & \\
\hline Less often & 27 (9) & $115(31)$ & $305(60)$ & $1.87(1.35$ to 2.59$)$ & $3.43(2.1$ to 5.58$)$ & $1.34(0.94$ to 1.92$)$ & 1.74 (0.86 to 3.54$)$ \\
\hline $\begin{array}{l}\text { Maternal smoking during } \\
\text { pregnancy } \times \text { household income }\end{array}$ & - & - & - & - & - & $0.87(0.4$ to 1.87$)$ & $0.21(0.06$ to 0.76$)$ \\
\hline
\end{tabular}

Unless otherwise stated, all items were measured at the first contact when the cohort child was aged around 34 months. $\mathrm{N}$ is the unweighted base. The percentages represent the weighted figures. Figures in bold represent $\mathbf{p}<0.05$.

who had inconsistently abnormal scores. Compared with children who did not have abnormal conduct problem scores at any time, children with any abnormal conduct scores were more likely in an adjusted model to have a younger mother, not to be living with both parents, to have another child in the household, to be in poor general health, to have difficulty being understood and to be rarely taken to visit other people with children. Conduct problems were also more likely to be reported by mothers who smoked during pregnancy and by parents who agree that smacking is sometimes necessary. These associations are broadly in line with findings from other cohort studies, which have reported predictors of conduct problems ${ }^{9}{ }^{10}$ and larger cross-sectional studies of psychiatric disorder among children. ${ }^{20}$

The implications of our findings nevertheless must be considered in relation to the design of the study. GUS data are obtained from the child's main carer, usually the child's natural mother and are therefore a measure of the parent's perception of the child's behaviour and interactions. Previous reports on the diagnostic validity of the $\mathrm{SDO}^{21-23}$ indicate that combinations of parent and teacher information provide the most robust data with the greatest sensitivity. On the basis of this validation work, we would anticipate some relative under-reporting of 
conduct difficulties by parents. Nevertheless, $27 \%$ of children had an abnormal score on the conduct scale of the SDQ at one or more collection points and $4.3 \%$ at all sampling times. Since life-coursepersistent $\mathrm{CD}$ is characterised by early onset and persistence, we consider it likely that there will be considerable overlap between children with persistently abnormal scores on the conduct subscale of the SDQ and those with this diagnosis. It is important to bear in mind, however, that no diagnostic assessment has been undertaken on these children and further follow-up will be necessary to establish a diagnosis. Furthermore, there may be some children who will go on to have a diagnosis of CD who did not have abnormal scores reported at all three time points reported here. The longitudinal stability of CD (and antisocial behaviour more broadly) is an important consideration in interpretation of our results. Significant fluctuations in conduct problems in preadolescence have been reported by a number of authors, ${ }^{24-26}$ and there are similar indications from our own data. Nevertheless, persistence of conduct problems in early childhood is a good early indicator for life-course-persistent CD, particularly for boys. ${ }^{24} 26$

A relationship between maternal smoking during pregnancy and antisocial behaviour has been described by several authors. At least part of the relationship may, however, be explained by confounding factors not examined in the present study. For example, in the e-risk cohort study, Maughan and colleagues ${ }^{27}$ found that around half of the association was attributable to genetic confounders. Mothers in that cohort who smoked during pregnancy were more likely themselves to have had antisocial behaviour and to have had children with more antisocial men. They were also living in more disadvantaged circumstances and were more likely to have had depression. Controlling for antisocial behaviour in both parents, depression in mothers, family disadvantage and genetic influences, estimates for the effects of prenatal smoking were reduced by between $75 \%$ and the entire initial effects. Nevertheless, regardless of causality, maternal smoking during pregnancy does appear to be a useful predictor of persistently reported child conduct problems. Similar considerations may apply to the relationship with parental separation and low household income described in the present study.

There were some notable differences between the characteristics of the inconsistent and persistent conduct problem groups. Low household income and maternal smoking during pregnancy were associated with persistent conduct problems substantially more strongly than with inconsistent conduct problems. There was also a strong negative interaction between poverty and smoking: among women who smoked during pregnancy those with low incomes were no more likely to have children with persistent conduct problems than those from higher-income families. This was not the case for children with inconsistent conduct problems. It is possible that this non-additive effect of poverty and smoking on persistent conduct problems reflects a view of smoking as more socially deviant in families living in more affluent circumstances. This in turn may be a consequence of some of the genetic factors postulated by Maughan, which are more likely to be salient in persistent conduct problems than in inconsistent problems. ${ }^{28}$ It is possible that there may be discrete genetic influences linking conduct problems with poverty (mediated, eg, through communication disorders ${ }^{29}$ ) and with smoking. ${ }^{30}$

Although male sex was not significantly associated with persistent conduct problems in our model, there was a male preponderance (59\% male in the persistent group and $54 \%$ in the inconsistent group). This corresponds reasonably closely with reports from cross-sectional studies of psychiatric disorder-for example, $69 \%$ of all cases of CD were male in the 2004 survey of mental health in the UK. ${ }^{20}$

\section{What is already known on this subject}

Life-course-persistent CD is a major public health problem, and a screening programme could be justifiable.

- Scoring systems for prediction of persistent conduct problems may help to identify children who may benefit from behavioural interventions.

- Some previous studies have identified a range of candidate physical and social predictors for CD.

\section{What this study adds}

- In a Scottish cohort study, several predictive factors were associated with conduct problems at age 3, 4 and 5 years.

- Compared with children with no conduct problems, children with reported problems were significantly more likely to have mothers who smoked during pregnancy. They were less likely to be living with both parents and more likely to be in poor general health, to have difficulty being understood, to have a parent who agrees that smacking is sometimes necessary and to be taken to visit other people with children rarely.

- Persistent and inconsistent conduct problems had similar risk factors, but associations with poverty and maternal smoking were significantly stronger in the persistent group.

Children with identifiable health problems at age 3 are at an increased risk of conduct problems. Delays in language development at the same age were also associated with conduct problems, compatible with previous findings of a strong relationship between language delay and psychopathology ${ }^{31}$ and school exclusion, ${ }^{32}$ in part related to peer rejection. ${ }^{33}$

Early parenting style was also related to persistent conduct problems. Belief in the efficacy of harsh discipline-smacking-at age 3 was, as expected, ${ }^{34} 35$ associated with conduct problems. Low frequencies of visits to other households with children were strongly associated with persistent and inconsistent conduct problems, but these family behaviour patterns may be responses to already difficult behaviour rather than precursors of it.

With longer follow-up, our model could potentially be used to derive a scoring system, which could allow health professionals to predict persistent CD during preventive child health contacts. Families of children identified in this way could be offered evidence-based parenting interventions, ${ }^{736}$ which would in turn need to be evaluated rigorously when used in this context.

Acknowledgements This research would not have been possible without the parents who participated in the Growing Up in Scotland (GUS) study; the GUS survey team; Scottish government for funding GUS; and the Scottish Centre for Social Research, the National Centre for Social Research, the University of Glasgow and the MRC Social and Public Health Sciences Unit for facilitating the production of this paper.

Contributors All authors contributed to the conception and design of the study. PW drafted the article, and PB and ST performed the statistical analyses with guidance from PW, HM, MH and GD who, along with $\mathrm{PB}$, contributed to the interpretation of the data. All authors approved the manuscript, and PW is the guarantor of the paper.

\section{Competing interests None.}

Ethics approval Ethics approval was provided by the Scotland 'A' MREC committee (application reference: 04/M RE 1 0/59).

Provenance and peer review Not commissioned; externally peer reviewed. 
Data sharing statement All the data presented here are now available to those members of the public who are able to obtain an ATHENS password.

Open Access This is an Open Access article distributed in accordance with the Creative Commons Attribution Non Commercial (CC BY-NC 3.0) license, which permits others to distribute, remix, adapt, build upon this work non-commercially, and license their derivative works on different terms, provided the original work is properly cited and the use is non-commercial. See: http://creativecommons.org/ licenses/by-nc/3.0/

\section{REFERENCES}

1. Wilson P, Minnis $H$, Puckering $C$, et al. Should we aspire to screen preschool children for conduct disorder? Arch Dis Child 2009:94:812-16.

2. Moffitt TE, Caspi $A$, Harrington $\mathrm{H}$, et al. Males on the life-course-persistent and adolescence-limited antisocial pathways: follow-up at age 26 years. Dev Psychopathol 2002;14:179-207.

3. Campbell S. Hard-to-manage preschool boys: externalizing behavior, socia competence, and family context at two-year followup. J Abnorm Child Psychol 1994:22:147-66

4. Moffitt TE, Caspi A, Dickson N, et al. Childhood onset versus adolescent onset antisocial conduct problems in males: natural history from ages 3 to 18 years. Dev Psychopathol 1996;8:399-424.

5. Shaw DS, Owens EB, Vondra Jl, et al. Early risk factors and pathways in the development of early disruptive behavior problems. Dev Psychopathol 1996;8:679-99.

6. Dube SR, Felitti VJ, Dong M, et al. The impact of adverse childhood experiences on health problems: evidence from four birth cohorts dating back to 1900. Prev Med 2003;37:268-77

7. Hutchings $\mathbf{J}$, Gardner $F$, Bywater $T$, et al. Parenting intervention in Sure Start services for children at risk of developing conduct disorder: pragmatic randomised controlled trial. BMJ 2007;334:678.

8. Nowak C. Heinrichs N. A comprehensive meta-analysis of Triple P-Positive Parenting Program using hierarchical linear modeling: effectiveness and moderating variables. Clin Child Fam Psychol Rev 2008;11:114-44.

9. Elberling $\mathbf{H}$, Linneberg $A$, Olsen $E$, et al. The prevalence of SDO-measured mental health problems at age $5-7$ years and identification of predictors from birth to preschool age in a Danish birth cohort: the Copenhagen Child Cohort 2000. Eur Child Adolesc Psychiatry 2010;19:725-35.

10. Murray J, Irving B, Farrington DP, et al. Very early predictors of conduct problems and crime: results from a national cohort study. J Child Psychol Psychiatry 2010:51:1198-207.

11. Thompson L, Kemp J, Wilson P, et al. What have birth cohort studies asked about genetic, pre- and peri-natal exposures and child and adolescent onset mental health outcomes? A systematic review. Eur Child Adolesc Psychiatry 2010;19:1-15.

12. Goodman R, Ford T, Simmons H, et al. Using the Strengths and Difficulties Questionnaire (SDQ) to screen for child psychiatric disorders in a community sample. Int Rev Psychiatry 2003;15:166-72.

13. Goodman R. Psychometric properties of the strengths and difficulties questionnaire J Am Acad Child Adolesc Psychiatry 2001:40:1337-45.

14. Goodman R. The strengths and difficulties questionnaire: a research note. J Child Psychol Psychiatry 1997;38:581-6.

15. Warnick EM, Bracken MB, Kasl S. Screening efficiency of the child behavior Checklist and strengths and difficulties questionnaire: a systematic review. Child Adolesc Ment Health 2008:13:140-7.
16. D'Unger AV, Land KC, McCall PL, et al. How many latent classes of delinquent/ criminal careers? Results from mixed poisson regression analyses. Am J Sociol 1998; 103:1593-630.

17. Jones BL, Nagin DS, Roeder K. A SAS procedure based on mixture models for estimating developmental trajectories. Sociol Methods Res 2001;29:374-93.

18. Begg CB, Gray R. Calculation of polychotomous logistic regression parameters using individualized regressions. Biometrika 1984;71:11-18.

19. Long JS, Freese J. Regression Models for Categorical Dependent Variables Using Stata. 2nd edn. College Station, TX: Stata Press, 2006.

20. Greene H, McGinnity A, Meltzer H, et al. Mental Health of Children and Young People in Great Britain, 2004. Basingstoke, Hants.: Palgrave MacMillan, 2005.

21. Goodman R, Ford T, Simmons H, et al. Using the Strengths and Difficulties Questionnaire (SDQ) to screen for child psychiatric disorders in a community sample. Br J Psychiatry 2000;177:534-9.

22. Sanne B, Torsheim $T$, Heiervang $E$, et al. The strengths and difficulties questionnaire in the Bergen Child Study: a conceptually and methodically motivated structural analysis. Psychol Assess 2009:21:352-64.

23. Sayal K, Goodman R. Do parental reports of child hyperkinetic disorder symptoms at school predict teacher ratings? Eur Child Adolesc Psychiatry 2009;18:336-44.

24. Pevalin DJ, Wade TJ, Brannigan A. Precursors, consequences and implications for stability and change in pre-adolescent antisocial behaviors. Prev Sci 2003:4:123-36.

25. Fontaine N, Carbonneau R, Barker ED, et al. Girls' hyperactivity and physical aggression during childhood and adjustment problems in early adulthood: a 15-yea longitudinal study. Arch Gen Psychiatry 2008;65:320-8.

26. Broidy LM, Nagin DS, Tremblay RE, et al. Developmental trajectories of childhood disruptive behaviors and adolescent delinquency: a six-site, cross-national study. Dev Psychol 2003:39:222-45.

27. Maughan B, Taylor A, Caspi A, et al. Prenatal smoking and early childhood conduct problems: testing genetic and environmental explanations of the association. Arch Gen Psychiatry 2004;61:836-43.

28. Moffitt TE. Adolescence-limited and life-course-persistent antisocial behavior: a developmental taxonomy. Psychol Rev 1993;100:674-701.

29. Gilmour J, Hill B, Place M, et al. Social communication deficits in conduct disorder: a clinical and community survey. J Child Psychol Psychiatry 2004:45:967-78.

30. McClernon FJ, Kollins SH. ADHD and smoking: from genes to brain to behavior. Ann N Y Acad Sci 2008;1141:131-47.

31. Miniscalco C, Nygren G, Hagberg B, et al. Neuropsychiatric and neurodevelopmental outcome of children at age 6 and 7 years who screened positive for language problems at 30 months. Dev Med Child Neurol 2006;48:361-6.

32. Ripley K, Yuill N. Patterns of language impairment and behaviour in boys excluded from school. Br J Educ Psychol 2005;75:37-50.

33. Menting B, van Lier PAC, Koot HM. Language skills, peer rejection, and the development of externalizing behavior from kindergarten to fourth grade. $J$ Child Psychol Psychiatry 2011;52:72-9.

34. Chang L, Schwartz D, Dodge KA, et al. Harsh parenting in relation to child emotion regulation and aggression. J Fam Psychol 2003;17:598-606

35. Weiss B, Dodge KA, Bates JE, et al. Some consequences of early harsh discipline: child aggression and a maladaptive social information nrocessing style. Child Dev 1992:63:1321-35.

36. Morawska A, Sanders MR. Self-administered behavioral family intervention for parents of toddlers: Part I. Efficacy. J Consult Clin Psychol 2006;74:10-19. 


\section{Correction}

Wilson P, Bradshaw P, Tipping S, et al. What predicts persistent early conduct problems? Evidence from the Growing Up in Scotland cohort. J Epidemiol Community Health 2013;67:76-80. The ages in the introduction, methods, results section and table 1 have been corrected from 34, 46 and 58 months to 46, 58 and 70 months. Also the statical methods section and the footnote in table 2 have been corrected from 34 months to 46 months.

J Epidemiol Community Health 2015;69:815. doi:10.1136/jech-2011-200856corr1

CrossMark 